\title{
Traffic (safety) culture and alcohol use: cultural patterns in the light of results of the SARTRE 4 study
}

\author{
Christopher Schlembach $^{1}$ - Gerald Furian ${ }^{1}$ - Christian Brandstätter ${ }^{1}$
}

Received: 14 April 2015 / Accepted: 27 January 2016/Published online: 12 February 2016

(C) The Author(s) 2016. This article is published with open access at SpringerLink.com

\begin{abstract}
Purpose Culture is put centre stage not only in contemporary social science, but also in safety research. In this paper we ask whether a safety culture exists in contemporary traffic systems across Europe and how it might look like by constructing a conceptual scheme of traffic safety culture with reference to Talcott Parsons' theory of social action. We refer to cultural patterns of alcohol use as alcohol is one of the most important safety issues alongside with speeding and fatigue. Culture is internalised by car drivers in terms of attitudes which organise motivational processes. Cognitive, emotional (cathectic) and evaluative attitudes can be distinguished.

Methods We apply this scheme to data that were collected in the course of the SARTRE 4 survey in which attitudes and opinions concerning road safety and accident causation in 18 European countries were measured. Countries differ with reference to cognitive, emotional and moral dimensions.

Results The results are organised in a comprehensive scheme of emotional and moral cultural orientations which is by far not complete, but which shall guide analysis in future research. Conclusions The analysis does not dig deeply into the national cultural systems of road traffic at a national level, but it is sufficiently clear in order to distinguish different configurations of cultural patterns along the three dimensions of cognition, emotion and morality. Understanding these dimensions is useful in
\end{abstract}

This article is part of Topical Collection on TRA 2014 Human Factors and Safety

Christopher Schlembach

Christopher.schlembach@univie.ac.at

1 Austrian Road Safety Board, Vienna, Austria order to construct symbolic or cultural leverages (e.g. media campaigns) in order to make our streets safer.

Keywords Traffic safety culture $\cdot$ Alcohol $\cdot$ Attitudes · Theory of social action $\cdot$ SARTRE 4

\section{Introduction}

When Hale and Hovden [1] reviewed the development of the scientific study of safety in organizations, they identified three ages of safety. The first age lasted from the 19th century until Second World War and was concerned "with technical measures to guard machinery, stop explosions and prevent structures collapsing." The second age focused on "personnel selection, training and motivation as prevention measures, often based on theories of accident proneness." As late as in the 1990s and as a reaction "to the idea that health and safety could be captured simply by matching the individual to technology," management systems became the focus of development and research. More than a decade later, Özkan and Lajunen [2] applied this argument to safety in the context of road traffic and extended it by distinguishing four different paradigms that can be interpreted as a successive unfolding of analytical perspectives: The first period of road safety research and practice focused on technical safety measures, the second dealt primarily with behavioural and individual factors, the third was concerned with ergonomics and sociotechnical systems, and the fourth (contemporary) age deals with culture. Culture is a safety factor in its own right and became a focus of crystallization for developing safety measures and policies, especially in the US [3-5].

From a sociological point of view the four ages of safety are congruent with what Talcott Parsons and his collaborators at the beginning of the 1950 s called the action frame of 
reference [6]. In this tradition human action is interpreted in four different perspectives which are of functional significance for every system of action and which cannot be reduced to one another. These four components are (1) the relationship between organism and environment in terms of adaption (mastering environmental conditions), (2) the personality of the individual actor, capable of goal-oriented and purposeful activity (which also constitutes the political dimension), (3) the integration of two or more actors with their mutual expectations within social systems and (4) the cultural patterns based on which actors convey the meaning of their behaviour to other actors or translate action into material forms (products, works of art, etc.). Arranged in a sequence (adaption, goal attainment, integration, latent pattern maintenance), the four components of human action constitute the phase movements of interaction processes in general [7]. The four stages of traffic safety, then, could be interpreted as a process of unfolding around the roster of these four functional perspectives.

The identification of the four safety management paradigms with the four analytical functional perspectives of the action frame of reference is also justified by the fact that road traffic can be interpreted as a system of human interaction in which safety is a prerequisite of its adequate functioning. If we assume that the transportation of goods and persons to places where they are needed is the purpose of the traffic system, its functional significance certainly lies in surmounting space (and time), hence adaption and mastering environmental conditions. But traffic can also be interpreted as a social system in which traffic participants interact in their roles as pilots of "vehicular units" in ways that help them avoiding collision. To be sure, safety in these terms is a prerequisite of system functioning, but even in these terms a culture must be established which shapes the ways of save conduct. Interaction is possible if actions of other actors are understandable and, in a way, predictable in order to orient one's own actions towards them, hence, some shared rules and standards of conduct are necessary [8]. These cultural patterns obtain normative significance and norms must be legitimated in order to become effective, especially where social control through formal sanctions is weak and where conformity relies much more on individual good will and compliance. Safety can obtain the role of a value from which the legitimation of norms are derived. In these terms, safety is not only a prerequisite for system functioning in a technical sense, as an implicit goal or a necessary condition of transportation. It is also a cultural value which puts the protection of transported persons and goods centre stage as an end in itself and organizes action processes towards safety as a goal that has to be realized by individual actors. The difference between safety as a necessary condition and safety as a cultural value is that in the first context it is part of adequate practical conduct (driving, cycling, etc.) whereas in the second context it is a desired state of the traffic system.

The values of a social system can be interpreted as a system in its own right, the cultural system, which is constituted by a more or less coherent and consistent pattern of different values. In many traffic cultures values which express safety are related to other values like comfort, aesthetic design, expression of social position (prestige), or values that are closer to the core values of the economy, that is, of efficiency and effectiveness. The fourth age of safety, we could infer, deals with the role of (road) safety as a value in our culturally patterned ways of mastering the environment, attaining goals and of interacting with other human beings (mutual passing by being a marginal case of interaction). This fact, however, does not mean that safety is automatically a core value of the traffic system. It finds its place among other values, sometimes in compatible, sometimes in conflicting ways.

Using the action frame of reference in the tradition of Parsons as a point of departure, we look just at one component of the cultural system that is related to road safety in order to show how this research perspective can be conceptualized: the relationship between drinking and driving in Europe. With the rise of automobility in the second half of the 20th century, alcohol became a major safety problem for road traffic worldwide [9]. Large scale research projects, from the pioneering work of Robert Borkenstein ("Grand Rapids Study") [10] up to the DRUID - Driving under the Influence of Drugs, Alcohol and Medicine EU-Project [11] documented the relationship between drinking and driving in rich detail. In the European context, alcohol is a very old, widespread, easily available and relatively cheap "cultural drug" in all European countries [12]. Many countries introduced alcohol limits for car drivers and cyclists as well as sanctions (the most widespread countermeasure) for their infraction [13, 14]. However, sanctions and legal regulations are part of the explicit culture; we are more interested in the "implicit culture" which is reflected in opinions, attitudes and patterns of behaviour. In this paper we ask whether a "traffic safety culture" is crystallized around the problem of alcohol use in these terms. Following a definition given by the US Department of Transportation (USDOT) [5], we define traffic safety culture as " $[\mathrm{t}]$ he shared values, actions, and behaviors that demonstrate a commitment to safety over competing goals and demands." This demonstration of safety beyond the practical requirements of safe, i.e. reasonably adequate conduct in order to realize transportation goals, is at stake in the cultural approach towards safety in transportation.

Our argument has the following structure: (1) We outline a conceptual scheme of how culture can be understood as a component of social action. (2) We ask whether patterns of a safety culture with reference to alcohol use prevail in various traffic systems. For this purpose we analyse data that were generated in the course of the SARTRE 4 project [14], a large 
scale survey on attitudes and opinions concerning road safety among 18 EU countries and Israel. Our analysis will not be a fully-fledged description of a cultural system, but just takes out some elements in order to show, how analysis could be conceptualised. (3) Pointing out where our analysis falls short, we will make some suggestions for further research in the field.

\section{Culture and the action frame of reference}

Our empirical starting point is the fact that the traffic system is probably the largest subsystem of modern society. Unlike organisations with their clearly defined (exclusive) membership status and occupational roles, road traffic is an open and highly inclusive system based on situational roles (drivers, pedestrians, cyclists, etc.) with low thresholds of participation. (Professional drivers constitute a zone of intersection between the situational and the occupational definition of roles.) Parsons conceptualises culture within a framework of systems of interaction of a plurality of actors and argues that it is a prerequisite for the functioning of interaction systems. A common culture allows the articulation of actors with social systems (roles) as the basis of reciprocity of action orientation (including conflict) as well as integration of different systems of action [6]. Culture is conceptualised in the tradition of US American social anthropology [15] as a set of symbolic patterns that tend to be organised in systems (e.g. classifications, styles, etc.) and that must be objectified in symbolic forms in order to be transmittable through space and time.

Within the theory of action, cultural patterns constitute the basic forms that shape the meaning of action in terms of motivation and decision making. The modes of motivational orientation can be classified as cognitive, cathectic (or expressive, emotional bonding between actors or between actors and norms), and evaluative orientations. Evaluative orientations are a combination of the first and the second type of motivational orientation. Cognitive orientations are organised in systems of ideas or beliefs. Cathectic orientations are organised in systems of expressive (emotional) symbols, and evaluative orientations consist of systems of value-orientations. It is the evaluative dimension which introduces reflections about consequences of actions and invokes value standards. Systems of cognitive symbols (beliefs) organise ways of cognising, systems of expressive symbols organise ways of cathecting, and systems of value symbols organise ways of evaluating. Ways of evaluating are necessary in order to resolve conflicts between divergent beliefs (cognitions) or divergent wants (cathexes) of individuals in a concrete situation.

In order to understand decision making, evaluative standards (value-orientations) are the most important. Like the basic modes of motivational orientation themselves, evaluative standards can be classified by the same threefold structure, that is, by cognitive standards (norms of truth), cathectic standards (norms of appreciation) and moral standards (norms of accepted behaviour) which can be formulated as alternatives of decision making.

In the context of evaluation, safety can be a cognitive problem that poses the question: is this a dangerous situation or a safe one? It can be a cathectic problem: is it appreciated to behave in ways that guarantee safety or is it appreciated to maximise pleasure? And it can be a moral problem: is it morally opportune to act in risky ways that endanger the actor or others who are involved in the situation, or is it a moral failure to do so? A culture in which safety is a core value will score high on one, two or all of the three levels, that is, on the levels of cognition (e.g. adequate risk perception), expression (safe conduct will be admired, drivers will display solidarity to one another) and morality (endangering others is morally condemned and sanctioned). In our empirical exemplification we will just focus on the group of car drivers and on one aspect of the cultural pattern that concerns alcohol use which, together with speeding, fatigue, distraction and not waring safety belts belongs to the major problems of road safety. Moreover, we will give some examples of how the three evaluative patterns of culture (cognition, expression and morality) can be estimated from the SARTRE 4 data.

\section{Method and data}

SARTRE 4 is the fourth wave of a large scale international survey which goal was to evaluate key aspects of road safety from the perspective of affected road user groups, as well as to represent national opinions and attitudes in European comparison. The survey addressed knowledge of traffic laws and road traffic risks, attitudes regarding road safety issues, reported road traffic behaviours, transport habits and needs [14].

SARTRE 4 continues the previous three phases of the project and is including - following the European Commission's recommendations for vulnerable road users - additional target groups in the survey. The current study, which was finalised in late 2012, was conducted in 19 countries among drivers, motorcyclists and non-motorised road users. One country, Israel, is not part of Europe in the narrow sense, but is included because of its European cultural heritage.

The surveys were carried out in form of face-to-face interviews (exception: Netherlands). Target sample size was 1000 exploitable records for each country, divided into the following subsamples: $n=600$ car drivers, $n=200$ powered two wheelers and $n=200$ other road users per country. Subgroups are representative of their corresponding population (quota variables were sex, age and occupation). For the purpose of this paper, we just focus on the car driver subsample. 
The SARTRE 4-questionnaire addressed a large number of traffic safety aspects, including the subjects speed, usage of restraint-systems, usage of helmets and protective motorcycle clothing, dangerous behaviour on the road, driving under the influence of alcohol or drugs, driving with fatigue, accident experience, environmental aspects, usage of driver assistance systems, evaluation of infrastructure measures, perceived causes of accidents, changes to legislative actions and motives for not using a car or motorcycle.

Our analytical strategy is rather simple and aims at classifying the material under scrutiny along the dimensions of cultural patterns we just have outlined above. For purposes of classification of culture we constructed a property space [16] with three dichotomies along the three dimensions of cognition, cathexis and evaluation. Cognition is conceptualized in terms of risk perception; drivers are classified as having higher or lower risk awareness. Expression is conceptualised in terms of the emotional attitude towards rule-infraction; drivers are classified as being more or less indifferent towards punishment. Morality is conceptualised in terms of the degree by which action shall follow normative standards; drivers are classified as morally more or less permissive. For our conceptualization of culture, this implies that we analyse cultural patterns as they are represented by individuals. It does not matter, however, whether an attitude or opinion is based on convictions or on orienting on beliefs about what other traffic participants think. This question points to what in social psychology is known as perceived (social) norms [17]. We do not intend to dive into this discussion, however, it shall be remarked that the cultural dimensions are not just individual, but socially shared patterns.

As we did a re-analysis of a survey which covered a range of questions, we just took the questions which addressed alcohol use and matched them with one of the three dimensions. We calculated the means of the responses for each country and also calculated the total mean. In order to match results with our dimensions of our property space we use the total mean as a discriminator where relatively lower levels of a dimension change to relatively higher levels.

\section{Results}

Let us first have a look at the behavioural patterns of drinking and driving. There are two types of association between alcohol and driving: (1) the use of alcohol within the legal limits and (2) the transgression of the legal limits. The first type partly refers to the old distinction between wet and dry cultures [18]. In wet cultures alcohol consumption tends to be moderate, but on a daily basis; dry cultures organise alcohol consumption around weekends where drinking can be excessive. The first type of association was addressed by the question: how often does someone drive after having drunken just a little bit alcohol? Responses were measured on a fivepoint ordinal scale (never, rarely, sometimes, often, and always). Figures 1 and 2 shows the percentages of those who affirmed that they have at least sometimes drunken just a little bit alcohol over the last month.

The second type of association between drinking and driving was addressed by asking: "Over the last month, how often did you drive a car, when you may have been over the legal limit for drinking and driving?" In this context we distinguished the group of those who did and those who did not infringe the law by drinking above legal limit (see Fig. 3).

In some countries which have a $0 \%$ alcohol limit like Poland the two questions cannot be distinguished from one another. The old distinction between wet and dry alcohol cultures is reflected in the patterns as shown in Fig. 2. Spain, Austria, France or Italy are typical wet cultures whereas the Nordic countries and some former eastern countries like Poland and Hungary appear to be dry cultures. This pattern is roughly in line with reference to drinking above the alcohol limit. Countries in which drinking and driving is part of everyday life routines (habits of taking meals and patterns of using cars) also seem to have tendencies towards transgressions of legal limits. A further description of the cultural configuration in terms of the three-dimensions of action motivation shall elucidate these finding.

The cognitive component is the first which we want to discuss. In the cognitive dimension we ask whether a driver interprets the situation in a way that allows him to master it in a secure and safe manner. Responses to two statements addressed this component in the SARTRE 4 study: (1) "You can drink and drive if you drive carefully" and (2) "Drinking and driving increase the risk of an accident with another road user." Responses to both questions were measured by a 4point Likert scale. For both question we used the total mean as a discriminator between higher and lower levels of the cognitive safety orientation.

There is a rather narrow range of results with respect to both questions (see Figs. 4 and 5). This fact is not surprising if we consider the initial reason for asking these questions.

Motivational
orientation
- Cognitive
- Cathectic
- Evaluative: brings in
thought for
consequences and
can invoke value
standards

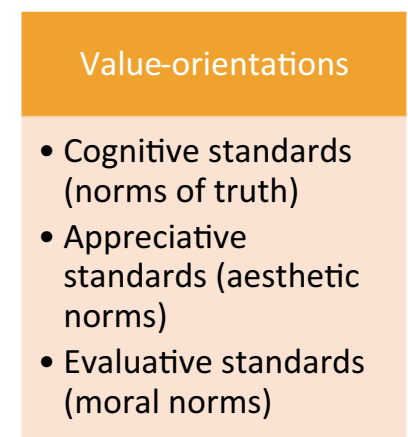

Fig. 1 Motivational orientations and value orientations according to Parsons. Source: [6] 
Fig. 2 Drivers who affirmed that they have at least sometimes drunken just a little bit alcohol over the last month $(N=12,457$, standard error between 0.0 and $+/-0.1 \%$, based on $95 \% \mathrm{CI}$ )

Source: SARTRE 4-data

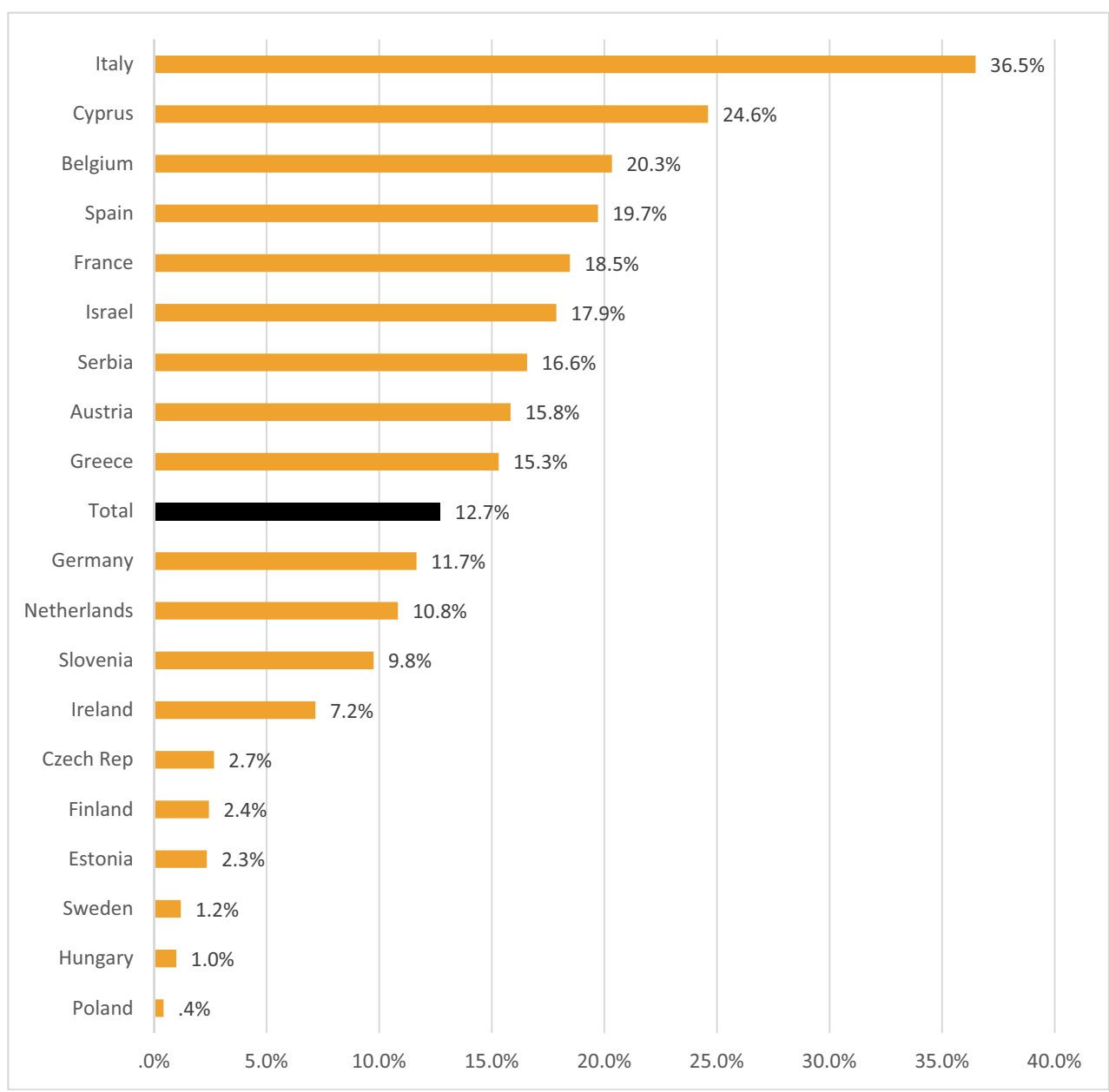

Basically they served as a measure for estimating the size of the group of alcohol users which as a result of longstanding campaigning and severe sanctioning is not very large in any European country [19]. Heavy alcohol users and pathological drinkers tend to deny the risk of being involved in an accident and overestimate their abilities to drink and drive carefully [20]. With respect to this fact, the readiness of drinkers to participate in road traffic on the cognitive level is measured. Campaigning against drinking and driving gave way to the development of alcohol averse cultural patterns in all countries, but still it makes a difference, whether 2,2\% (Greece) of the population think that you can drink if you drive carefully or $17,5 \%$ (Belgium).

For further classification we use the dichotomised results of both questions and label countries in which both questions score below the total mean as cultures of higher risk awareness. Cultures in which the cognitive orientation scores above the total mean at least in one question are qualified as having lower levels risk awareness. The countries which scored below the total mean with regard to both questions and to which, therefore, we attributed higher levels of risk awareness are: Estonia, Finland, Germany, Greece, Hungary, Slovenia,
Spain and Sweden. In highly risk aware cultures a residual group of alcohol users still exist and is to some extent represented by the two items mentioned above, but it is much smaller compared to cultures of lower risk awareness which we suppose being less encouraging to see the risk of drinking and driving.

If we look at the expressive (cathectic) component, we could either use questions concerning the pleasure of using alcohol or the degree of attachment to norms. The SARTRE 4 study included one question with reference to normative orientation which can be interpreted in the context of cathectic meaning: "If you drink and drive you will be stopped and fined by the police." With respect to this dimension of action orientation, we distinguish between more or less indifferent "penal" cultures. It is not the moral evaluation that is in the focus of this question, but the fear of punishment and the negative feelings associated with it. Italy is the most indifferent culture in this respect whereas France scores highest on fear of punishment (see Fig. 6).

This result is interesting as both countries are wet cultures, but they integrate alcohol quite different with driving. One reason for this might be the institutionalized side of the safety 
Fig. 3 Number of persons who drove after having drunken above the official alcohol limit $(N=12,458$, standard error between $+/-0,2 \%$ and $+/-0,8 \%$, based on $95 \% \mathrm{CI})$. Source: SARTRE 4-data

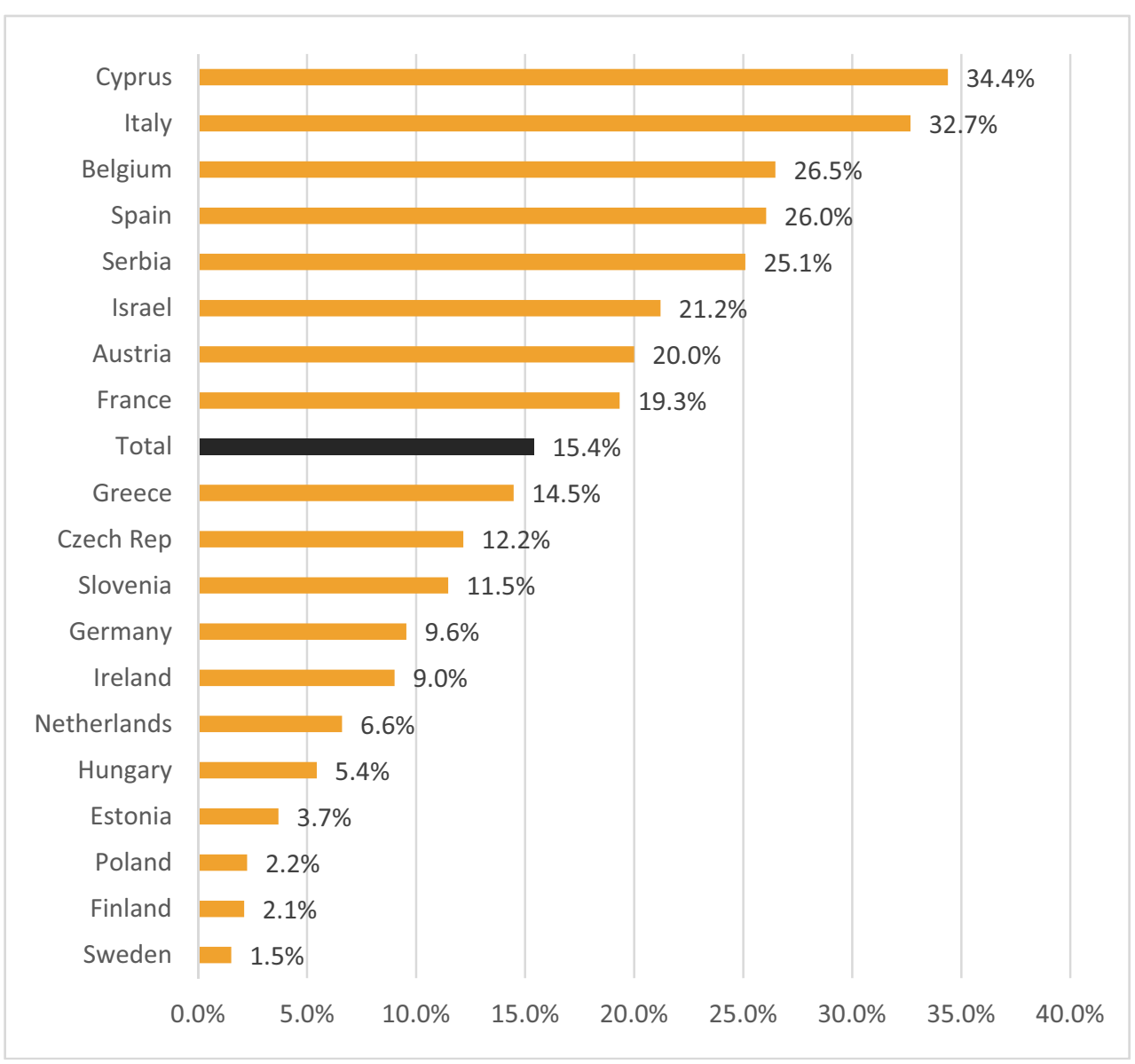

culture in terms of policing patterns. In fact, roadside police tests in France are almost 9 times more frequent than in Italy. Whereas in France in 2008, 190 roadside tests per 1000 population took place, in Italy it were just 23 per 1000 population [14]. This fact aligns with driver's subjective perceptions concerning police checks. A question of the SARTRE 4 study asked, how likely it is on a typical journey to be checked for alcohol. 27,9\% of the French drivers responded with never, whereas the number of drivers in Italy who said never was $46,8 \%$.

The third component is evaluation. We use a question concerning alcohol limits that should be permitted in the context of car driving. Responses were measured with a five point ordinal scale ranging from "no alcohol at all" to "as much as they want." Between these two extremes, respondents could opt for more or less alcohol as compared to the current legal limit. The fact that we are interested in is not the attitude towards alcohol limits as such, but the relationship between the given limits and the positive or negative deviations from an evaluative perspective. Again we use to total mean as discriminator and label countries in which car drivers would not permit any alcohol at all or at least as much as the legal limit prescribes as "morally restrictive" cultures. Countries in which car drivers would permit higher levels of blood alcohol than the legal limit or in which alcohol consumption should be completely free, are called "morally permissive." Austria is labelled morally restrictive according to our scheme of classification; Spain still is morally permissive (see Fig. 7). Countries with a zero tolerance policy, however, are a complication as they cannot vote for lower alcohol limits. They can just accept the status quo or opt for a less restricted legal limits, hence be more permissive.

If we cross-tabulate this three-dimensional property space of culture along the cathectic and evaluative dimensions we get the following results:

Finland is the only country which scores high in all three dimension. In this case, safety tends to be reflected in the cognitive, the expressive (emotional) and in the evaluative (moral) dimension. Estonia, Greece, Hungary and Spain seem to be morally more permissive; their safety cultures with reference to alcohol emphasize cognitive and expressive elements. Germany, Slovenia and Sweden can be interpreted more in terms cognitive and moral safety cultures. They score lower in the expressive dimension. In Poland and France the safety relevant attitudes seem to be based on the moral and the expressive dimension whereas risk awareness inclines to be downplayed. Belgium and Cyprus tend towards an expressive safety culture; Austria, Ireland and the Netherlands 
Fig. 4 Percentages of drivers who "very" and "fairly" agree with that you can drink and drive if you drive carefully $(N=12,465$, standard error between $+/-0,2 \%$ and $+-0,6 \%$ based on $95 \% \mathrm{CI}$ ). Source: SARTRE 4-data)

Fig. 5 Percentages of drivers who "not much" or "not at all" agree that drinking and driving increases the risk an accident with another road user $(N=12,465$, standard error between $+/-0,2 \%$ and $+/-0,6 \%$ based on $95 \% \mathrm{CI}$ ). Source: SARTRE 4-data

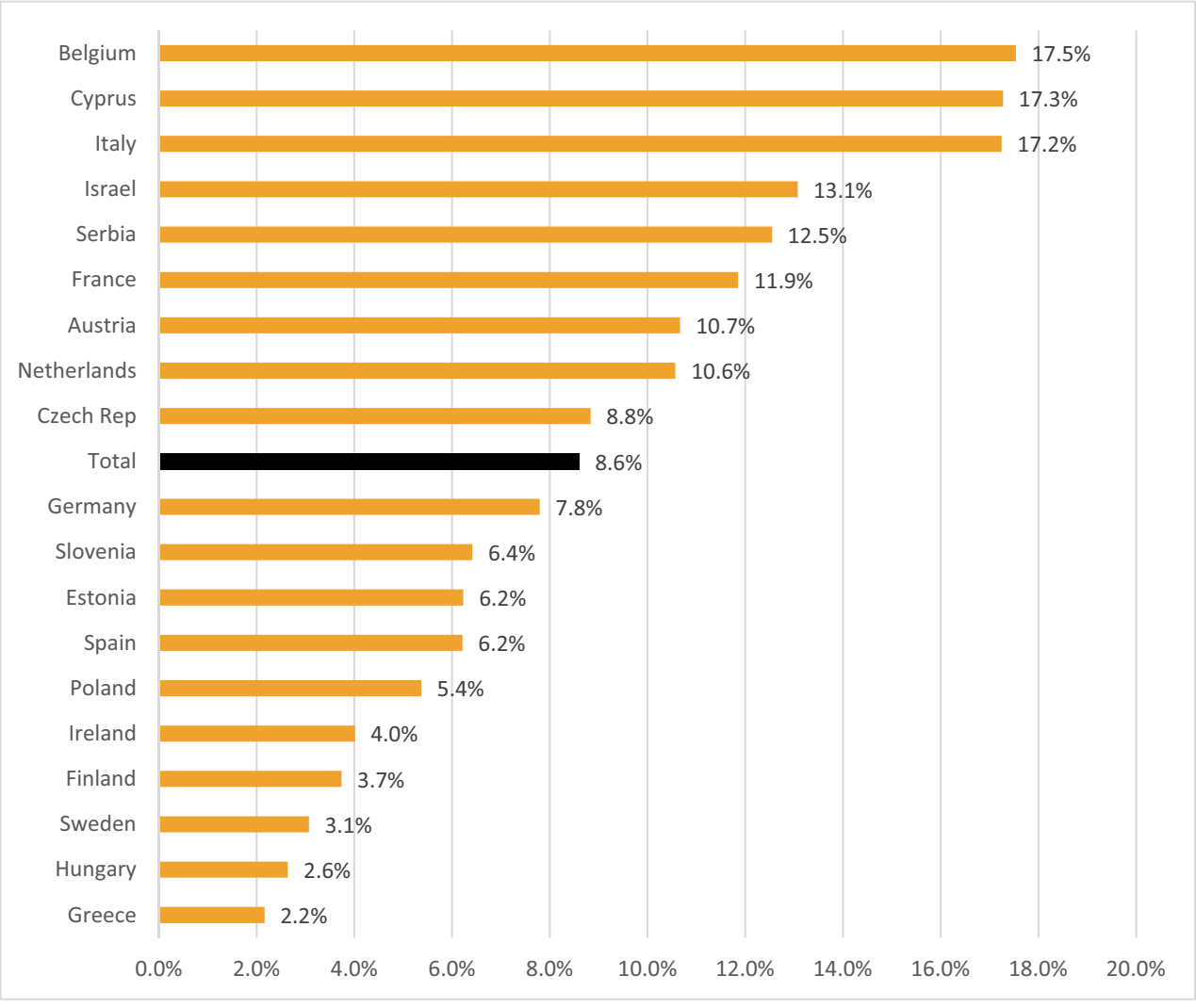


Fig. 6 Percentage of drivers that agree "very" and "fairly" with that if you drink and drive you will be stopped and fined by the police $(N=12,439$, standard error between $+/-0,4 \%$ and $+/-0,9 \%$ based on 95 CI, source: SARTRE 4-data)

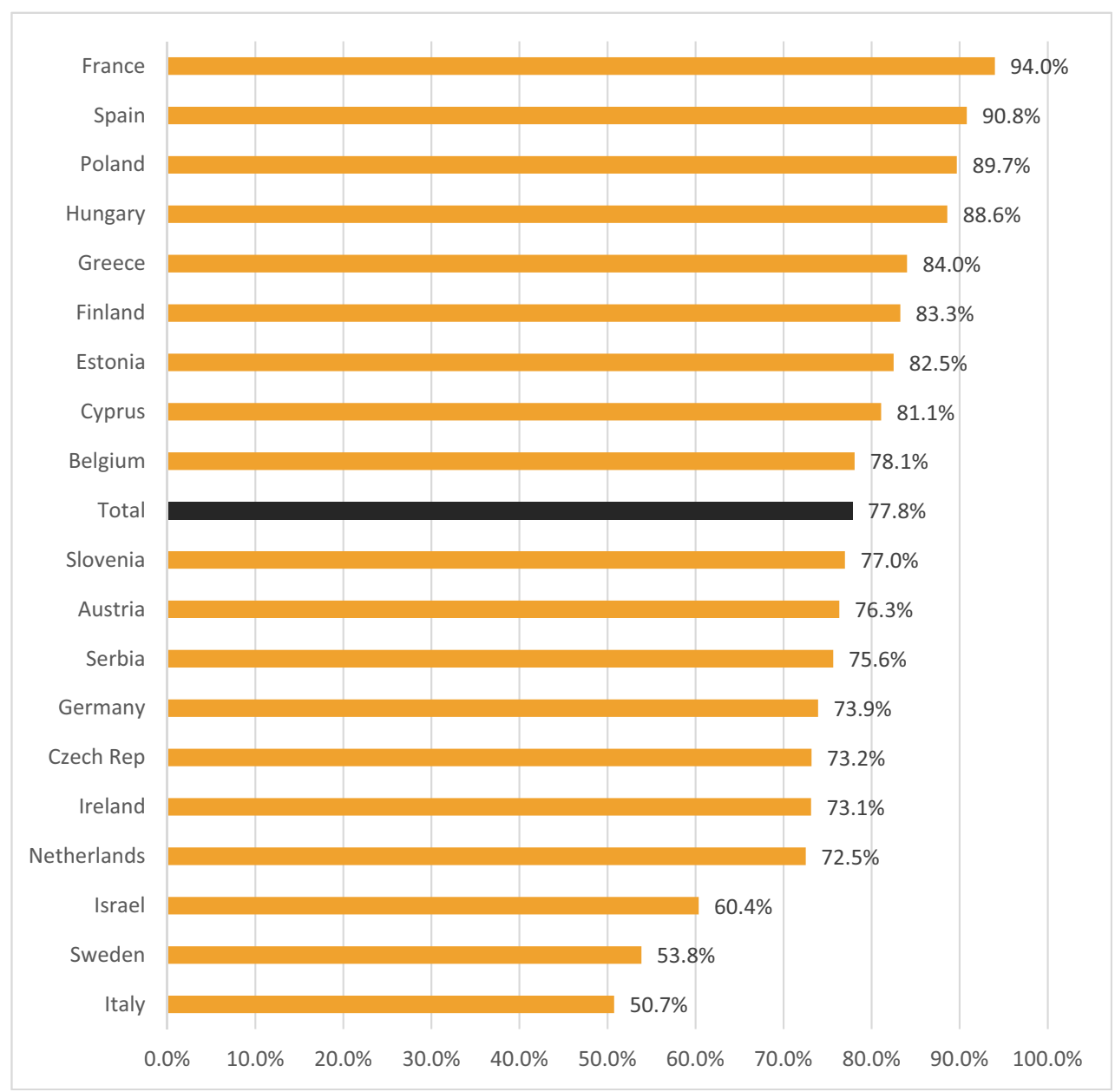

are countries in which safety culture seems to be based on morality. The Czech Republic, Israel, Italy and Serbia can be interpreted as having the weakest safety cultures. Thy score lower in all three dimensions.

An important question is whether findings have any relationship with alcohol related crashes and fatalities on the road. At the current state of our research, but also given the poor data situation, this question is hard to answer. In a recent study on the prevention of drink-driving by the use of alcohol interlock devices, an estimation of the share of drink-driving fatalities in Europe was carried out [21, p. 32-33]. It combined expert estimation, epidemiological studies and available official statistics in order to give a more realistic picture of the drink-driving problem among European countries. With the exception of Serbia and Israel, all countries that participated in the SARTRE 4 study were represented. For most countries, the share of drink-driving fatalities was expressed by an upper and a lower limit and applied to accident numbers from 2011. Austria, for example, ranges from $13 \%$ to $23 \%$ share of drink-driving fatalities which means in terms of absolute fatalities in 2011 (523) a range from 68 to 120 . For the most part, these estimates deviate dramatically from figures that are taken from official statistics, police records and other estimates as they are presented in the report of the International Traffic Safety Data and Analysis group (IRTAD) [22] or the EU road accidents database (CARE) [23]. Reasons for these deviations might be found in the legal system and in data collection practices. In the Netherlands, for example, it is not allowed to test deceased persons for psychoactive substance use and police registration regarding psychoactive substance use by seriously injured road users is said to be not reliable [22]. It is, therefore, very difficult to make any serious inference about the relationship between cultural orientations and drink-driving traffic fatalities.

Taking all these caveats into account, we compare our findings with these two sources. We take the estimated share of traffic fatalities from the alcohol interlock study [21] and the estimated share of fatalities as presented by the IRTAD report 2014 [22]. We match these two data sources with the type of alcohol related traffic safety culture that we inferred from interpreting the SARTRE 4 data (Tables 1 and 2). One immediately finds that France, which scores high in two of the three dimensions of safety culture, has also high rates of alcohol 
Fig. 7 Opinion about alcohol limits. Percentages refer to those respondents who are restrictive in the moral sense and opt for no alcohol at all, less alcohol than at present, or as much alcohol as at present. Percentages below the total mean are classified as morally more permissive $(N=12,460$, standard error between $0,0 \%$ and $+/-0,7 \%$ based on $95 \% \mathrm{CI}$ ). Source: SARTRE 4-data

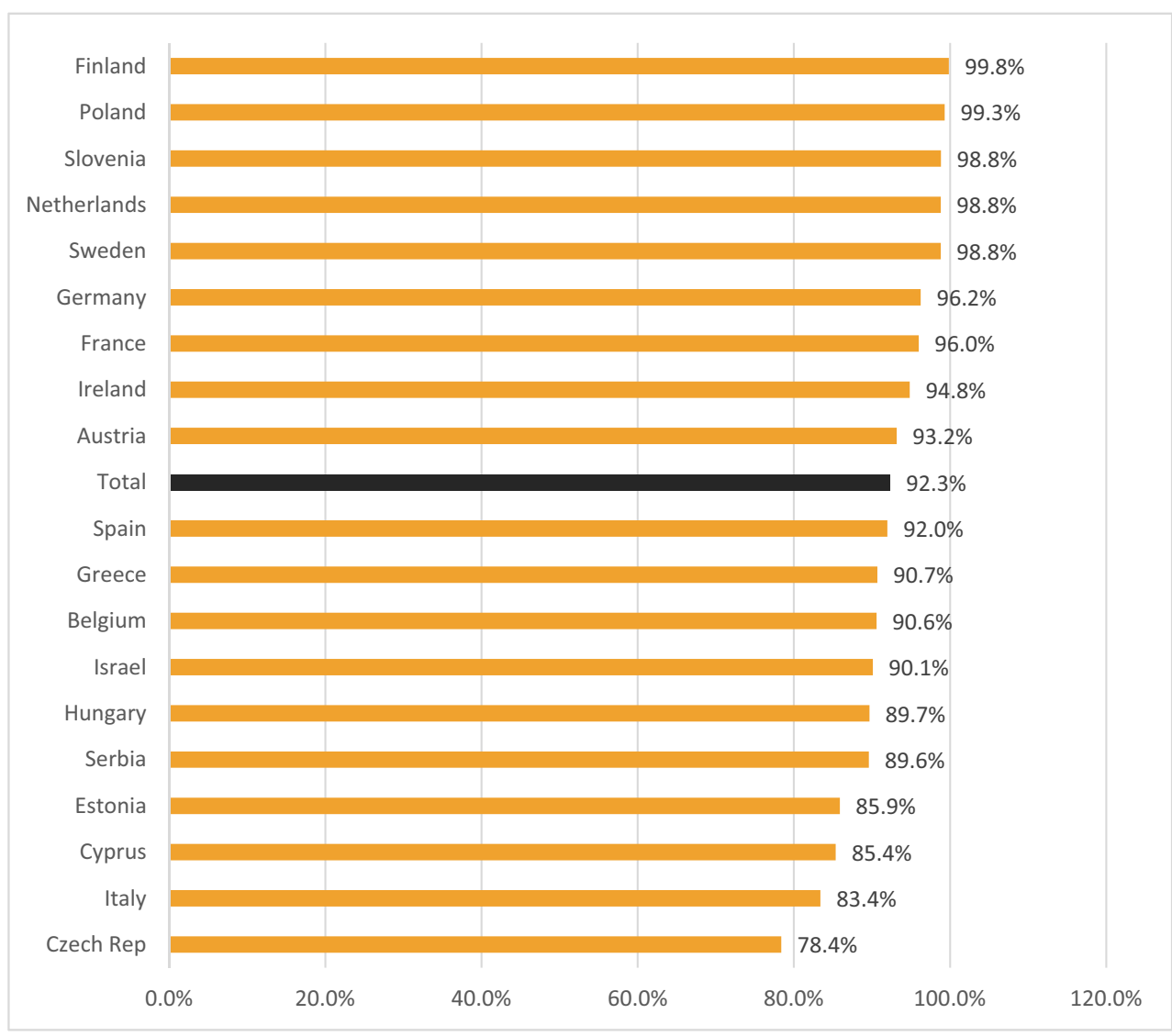

related traffic fatalities (about $30 \%$ in the IRTAD and the alcohol interlock study), but its overall traffic fatality rate is quite low. France is a wet culture, which is reflected in the fact that $44.6 \%$ of drivers affirm that they have at least sometimes drunken just a little bit alcohol over the last month. The chance that alcohol is involved in fatalities (especially below legal limit) might be higher. On the other hand, Italy seems to have a very low share of fatalities according to the IRTAD report, and a moderate share $(15,6-25,6 \%)$ according to the alcohol interlock study. However, the authors argue that the $2 \%$ share might be a gross underestimation of the real figure due to difficulties of colleting this information [22]. The message of this seems to be that the relationship between the safety culture and fatalities is complex and our conceptualization of safety culture by using the SARTE 4 data might be a starting point for further research that is able to give a much more adequate picture of the cultural patterns at work.

\section{Discussion}

In this paper we applied the analytical scheme as developed in the theory of social action to traffic safety culture with reference to alcohol use. The focus of our analysis are attitudes which can be interpreted as cultural patterns as far as they are institutionalised in (large scale) social systems and internalised by its members. We suggest this research perspective as an adequate starting point for further analysis. The

Table 1 Dimensions of traffic safety culture with reference to alcohol use

\begin{tabular}{|c|c|c|c|c|}
\hline & \multicolumn{2}{|c|}{ Cognitive: higher risk awareness } & \multicolumn{2}{|c|}{ Cognitive: lower risk awareness } \\
\hline & $\begin{array}{l}\text { Higher moral } \\
\text { restrictiveness }\end{array}$ & $\begin{array}{l}\text { Lower moral } \\
\text { restrictiveness }\end{array}$ & $\begin{array}{l}\text { Higher moral } \\
\text { restrictiveness }\end{array}$ & $\begin{array}{l}\text { Lower moral } \\
\text { restrictiveness }\end{array}$ \\
\hline Higher expression of norm-conformity & Finland & $\begin{array}{l}\text { Estonia, Greece, } \\
\text { Hungary, Spain }\end{array}$ & France, Poland & Belgium, Cyprus \\
\hline Lower expression of norm-conformity & $\begin{array}{l}\text { Germany, Slovenia, } \\
\text { Sweden }\end{array}$ & & $\begin{array}{l}\text { Austria, Ireland, } \\
\text { Netherlands }\end{array}$ & $\begin{array}{l}\text { Czech Republic, Israel, } \\
\text { Italy, Serbia }\end{array}$ \\
\hline
\end{tabular}


Table 2 BAC-levels, fatalities/100.000 population, estimated share of drink-driving fatalities in Europe according to the alcohol interlock study (Ecorys) and the IRTAD report compared to the dimensions of traffic safety culture. Sources: [21-23]

\begin{tabular}{|c|c|c|c|c|c|c|c|c|}
\hline & $\begin{array}{l}\text { BAC- } \\
\text { level }\end{array}$ & $\begin{array}{l}\text { Fatalities/100.000 } \\
\text { inhabitants in } 2012 \\
\text { (IRTAD, CARE*) }\end{array}$ & $\begin{array}{l}\text { Share of drink- } \\
\text { driving fatalities in } \\
\text { Europe (Ecorys) }\end{array}$ & $\begin{array}{l}\text { Share of drink-driving } \\
\text { involvement in traffic } \\
\text { fatalities in } 2012 \text { (IRTAD) }\end{array}$ & $\begin{array}{l}\text { Cognition } \\
(\text { mean }=8,6 / 5\end{array}$ & $5,9 \%)$ & $\begin{array}{l}\text { Cathexis } \\
(\text { mean }=77,8)\end{array}$ & $\begin{array}{l}\text { Morality } \\
(\text { mean = 92,3) }\end{array}$ \\
\hline Austria & 0,5 & $6,3 \%$ & $13-23 \%$ & $8,7 \%$ & $10,7 / 7,3 \%$ & lower & $76,3 \%$ lower & $93,2 \%$ higher \\
\hline Belgium & 0,5 & $6,9 \%$ & $33,2-43,2 \%$ & n.a. & $17,5 / 7,3 \%$ & lower & $78,1 \%$ higher & $90,6 \%$ lower \\
\hline Cyprus & 0,5 & n.a. & $43,3 \%$ & n.a. & $17,3 / 10,0 \%$ & lower & $81,1 \%$ higher & $85,4 \%$ lower \\
\hline Czech Rep & 0 & $7,1 \%$ & $10,0-25,0 \%$ & $6,6 \%$ & $8,8 / 8,5 \%$ & lower & $73,2 \%$ lower & $78,4 \%$ lower \\
\hline Estonia* & 0,2 & 6,6 & $30,0 \%$ & n.a. & $6,2 / 3,2 \%$ & higher & $82,5 \%$ higher & $85,9 \%$ lower \\
\hline Finland & 0,5 & $4,7 \%$ & $23,5 \%$ & $\begin{array}{l}16,0 \% \text { (BAC above } 0,5 \mathrm{~g} / 1 \\
\text { limit) }\end{array}$ & $3,7 / 0,3 \%$ & higher & $83,3 \%$ higher & $99,8 \%$ higher \\
\hline France & 0,5 & $5,8 \%$ & $30,8 \%$ & $30,0 \%$ (over past 10 years) & $11,9 / 2,2 \%$ & lower & $94,0 \%$ higher & $96,0 \%$ higher \\
\hline Germany & 0,5 & $4,4 \%$ & $14,0-24,0 \%$ & $9,4 \%$ & $7,8 / 3,9 \%$ & higher & $73,9 \%$ lower & $96,2 \%$ higher \\
\hline Greece & 0,5 & $9,1 \%$ & $20,0-40,0 \%$ & n.a. & $2,2 / 5,0 \%$ & higher & $84,0 \%$ higher & $90,7 \%$ lower \\
\hline Hungary & 0 & $6,1 \%$ & $26,1-36,1 \%$ & $\begin{array}{l}11,2 \% \text { (personal injury } \\
\text { crashes). }\end{array}$ & $2,6 / 4,8 \%$ & higher & $88,6 \%$ higher & $89,7 \%$ lower \\
\hline Ireland & 0,5 & $3,5 \%$ & $29,8 \%$ & $15,5 \%$ (estimated in 2007$)$ & $4,0 / 7,7 \%$ & lower & $73,1 \%$ lower & $94,8 \%$ higher \\
\hline Israel & 0,5 & $3,3 \%$ & n.a. & $7-15 \%$ & $13,1 / 10,6 \%$ & lower & $60,4 \%$ lower & $90,1 \%$ lower \\
\hline Italy & 0,5 & $6,0 \%$ & $15,6-25,6 \%$ & $2,0 \%$ & $17,2 / 4,6 \%$ & lower & $50,7 \%$ lower & $83,4 \%$ lower \\
\hline Netherlands & 0,5 & $3,9 \%$ & $20,0-30,0 \%$ & $\begin{array}{l}28 \% \text { (seriously injured, } 2007- \\
2009 \text { ) }\end{array}$ & $10,6 / 2,9 \%$ & lower & $72,5 \%$ lower & $98,8 \%$ higher \\
\hline Poland & 0,2 & $9,2 \%$ & $8,0-18,0 \%$ & $9,0 \%$ (over past 10 years) & $5,4 / 9,5 \%$ & lower & $89,7 \%$ higher & $99,3 \%$ higher \\
\hline Serbia & 0,3 & $9,7 \%$ & n.a. & 5-7 \% (over past 10 years) & $12,5 / 14,7 \%$ & lower & $75,6 \%$ lower & $89,6 \%$ lower \\
\hline Slovenia & 0,5 & $6,3 \%$ & $35,5 \%$ & $34,0 \%$ & $6,4 / 4,8 \%$ & higher & $77,0 \%$ lower & $98,8 \%$ higher \\
\hline Spain & 0,5 & $4,1 \%$ & $31,0 \%$ & n.a. & $6,2 / 5,0 \%$ & higher & $90,8 \%$ higher & $92,0 \%$ lower \\
\hline Sweden & 0,2 & $2,7 \%$ & $20,0-30,0 \%$ & $24 \%$ & $3,1 / 2,4 \%$ & higher & $53,8 \%$ lower & $98,8 \%$ higher \\
\hline
\end{tabular}

picture we get does not dig deeply into the cultural systems of road traffic at a national level, but it is sufficiently clear in order to distinguish constellations of patterns which are adequate to the level of abstraction that was taken in the SARTRE 4 survey.

Some conjectures, however, can be inferred from our findings. Countries in which the safety relevant attitudes with reference to alcohol use are poorly established, have more difficulties with institutionalising effective legal measures like alcohol limits. Being part of the explicit culture, the norms do not resonate with the implicit culture in terms of cognitive, cathectic and evaluative orientations. For example a recent evaluation of the reduction of the legal limit for blood concentration in Serbia (from $0,5 \mathrm{~g} / 1$ to $0,3 \mathrm{~g} / \mathrm{l})$ did find only a limited effect on deadly traffic fatalities. It also found that in Serbia the emotional bonds towards the law (fear of punishment) as well as the moral standards and the levels of risk awareness are lower as compared to the European average [24].

Looking at road traffic from a social system perspective postulates that social systems in modern societies are based on a kind of solidarity of strangers which is the weakest form of attachment between actors. Social action, then, is based on mutually shared normative standards in terms of cognition, appreciation and evaluation. Although we used just two questions, it seems to be that the cognitive dimension of safety with reference to alcohol is relatively highly developed throughout Europe. The total means that sum up questions concerning the ability to drink and drive if you drive carefully and the denial of the relationship between drinking and accident risk are 8, $6 \%$ (Fig. 4) and 5,9\% (Fig. 5), hence not widespread beliefs. Decades of campaigning and education together with law enforcement and sanctioning on different levels made knowledge about the negative effects of alcohol on road safety available at an institutional basis. But the problem of alcohol use prevails to a more or less small degree in all driving cultures and there are two other important dimensions of attitudes which still can be addressed: these are the ways in which car drivers are attached to the normative standards and the standards by which they evaluate drinking and driving on moral grounds. Understanding these dimensions is useful in order to construct symbolic or cultural leverages (e.g. media campaigns) in order to make our streets safer.

We are still far away from an adequate understanding of the relationship between culture and accidents. Further research should operationalize the three cultural dimensions more fine grained and put them into relation with other values of the cultural system, in terms of attitudes (implicit culture), but also 
in terms of elements of the explicit culture (legal norms, media campaigns, training programmes, or scientific work). In a more sociologically oriented research perspective, cultural patterns should be studied at the levels of institutionalization (how they become part of role-expectations in social systems) and on internalization (how they become part of individual personalities).

\section{Limitations of the analysis}

To be sure, secondary analysis is always fraught with limitations. Using just one or two questions as indicators of a whole dimension of attitudes in social action is no perfect solution of the problem of measurement. Despite this rough approximation, however, the results suggest that the approach is fruitful in order to discuss traffic safety issues if items are constructed and scales are adjusted to the model. It is, in our view, a complementary perspective on traffic safety work, especially with reference to harmonize traffic safety guidelines at a European level. We also need better data for estimating alcohol involvement in crashes and fatalities. Currently available data are estimations that draw from different sources; official data are often unreliable and hard to compare.

Furthermore, there are some caveats for reading our classification. First it has to be read as a relational scheme. The different countries do not lack risk awareness, ascetic ideals and moral attitudes as such. But relative to other countries in our sample they have lower degrees concerning these safety related attitudes. Second these culture patterns are based on one or two questions and focus only on drinking and driving. We neither reconstructed the bigger picture of a safety culture nor did we investigate the relationship between cultural elements in terms of their consistency. The third caveat is that attitudes do not correspond directly with risk taking behaviour and other factors that concern traffic fatalities.

We also did not elaborate the social structure of these cultural patterns in terms of gender, age or class, nor did we take legal limits, levels of alcohol consumption and prevalence rates of pathological drinking into account. Avoiding the relationship between drinking and driving is well established in most European countries and what we, in a way, seem to explore, it the size of the "problem group" of those who still drink and drive.

Further research should place safety issues concerning alcohol use in context with other values in order to show how safety is anchored in different cultural systems as a whole.

However, we think that this type of analysis is relevant when we try to change patterns of action orientation into more secure ways of driving. It is important to know whether campaigns concerning drinking and driving should address cognitive, emotional or moral dimensions of action orientation. As our findings are preliminary and the relationship between culture and accidents needs much more elaboration, we hesitate to give any recommendations at this point.

Open Access This article is distributed under the terms of the Creative Commons Attribution 4.0 International License (http:// creativecommons.org/licenses/by/4.0/), which permits unrestricted use, distribution, and reproduction in any medium, provided you give appropriate credit to the original author(s) and the source, provide a link to the Creative Commons license, and indicate if changes were made.

\section{References}

1. Hale AR, Hovden J (1998) Management and culture: the third age of safety. A review of approaches to organizational aspects of safety, health and environment. In: Feyer A-M, Williamson A (eds) Occupational injury: risk. Prevention and Intervention. Taylor \& Francis, London, pp. 129-166

2. Özkan T, Lajunen T (2011) Chapter 14 - person and environment: traffic culture. In: Porter BE (ed) Handbook of traffic psychology. Academic Press, San Diego, pp. 179-192. doi:10.1016/B978-0-12381984-0.10014-1

3. AAA (2007) Improving traffic safety culture in the United States: the journey forward. AAA Foundation for Traffic Safety, Washington, DC

4. Ward NJ, Linkenbach J, Keller SN, Otto J (2010) White Paper on Traffic Safety Culture. White Paper No. 2. Western Transportation Institute. College of Engineering Montana State University, Bozeman

5. USDOT (2011) Safety culture: A significant driver for safety in transportation. Research paper prepared for the US DOT Safety Council. USDOT, Washington, DC

6. Parsons T, Shils EA (1951) Toward a General Theory of action. theoretical foundations for the social sciences. Harvard University Press, Cambridge

7. Parsons T, Bales RF, Shils E (1953) Phase movement in relation to motivation, symbol formation, and role structure. In: Parsons T, Bales RF, Shils E (eds) Working papers in the theory of action. The Free Press, Glencoe (Ill)

8. Goffman E (1971) Relations in public: microstudies of the public order. Basic Books, New York

9. Fabbri A, Marchesini G, Vandelli A (2004) 25 - alcohol and road accidents. In: Preedy VR, Watson RR (eds) Comprehensive handbook of alcohol related pathology. Academic Press, Oxford, pp. 309-320. doi:10.1016/B978-012564370-2/50027-1

10. Borkenstein RF, Crowther FR, Shumate RP, Ziel WB, Zylman R (1964) The role of the drinking driver in traffic accidents. Department of Police Administration, Indiana University

11. Schulze H, Schumacher M, Urmeew R, Auerbach K (2006) DRUID final report: work performed, main results and recommendations. Federal Highway Research Institute (BASt), Germany

12. Gordon R, Heim D, MacAskill S (2012) Rethinking drinking cultures: A review of drinking cultures and a reconstructed dimensional approach. Public Health 126(1):3-11. doi:10.1016/ j.puhe.2011.09.014

13. Watson BC, Leal NL, Soole DW (2013) Chapter 71 - the impact of drink Driving Laws. In: Miller PM (ed) Interventions for addiction. Academic Press, San Diego, pp. 697-707. doi:10.1016/B978-0-12398338-1.00071-3 
14. Cestac J, Delhomme P (2012) The SARTRE 4 survey: European Road users' risk perception and mobility. Public Imprim, Lyon

15. Kluckhohn C (1962) Culture and behavior: collected essays. The Free Press of Glencoe, New York

16. Barton AH (1955) The concept of property-space in social research. In: Lazarsfeld PF, Rosenberg M (eds) The language of social research. The Free Press, Glencoe (Ill), pp. 40-62

17. Rimal RN, Real K (2003) Understanding the influence of perceived norms on behaviors. Commun Theory 13:184-203

18. Melinder K (2007) Socio-cultural characteristics of high versus low risk societies regarding road traffic safety. Saf Sci 45(3):397-414. doi:10.1016/j.ssci.2006.07.004

19. Cestac J, Barbier C, Sardi G-M, Freeman R, Kraiem S, Assailly J-P (2014) Comparison of car drivers and motorcyclists' drink-driving in 19 countries, results from the SARTRE 4 survey. Paper presented at the TRA, Paris

20. Brown TG, Bhatti J, Di Leo I (2013) Chapter 22 - driving while impaired (treatments). In: Miller PM (ed) Interventions for addiction. Academic Press, San Diego, pp. 207-217. doi:10.1016/ B978-0-12-398338-1.00022-1

21. Ecorys, SWOV, ADV (2014) Study on the prevention of drinkdriving by the use of alcohol interlock devices: final report. Rotterdam, http://ec.europa.eu/transport/road_safety/pdf/behavior/ study_alcohol_interlock.pdf

22. International Traffic Safety Data and Analysis Group (2014) Road Safety Annual Report 2014: Summary, http://www. oecd-ilibrary.org/docserver/download/7514011e.pdf?expires= $1444985680 \& \mathrm{id}=\mathrm{id} \&$ accname $=$ guest $\&$ checksum $=$ FE2D41D22 47F5A052E45A01632725FBB

23. European Commission (2015) Road Safety Evolution in the EU by Population, http://ec.europa.eu/transport/road_safety/pdf/ observatory/historical_evol_popul.pdf

24. Živković V, Nikolić S, Lukić V, Živadinović N, Babić D (2013) The effects of a new traffic safety law in the republic of Serbia on driving under the influence of alcohol. Accid Anal Prev 53 (0): 161-165. doi:10.1016/j.aap.2013.01.012 